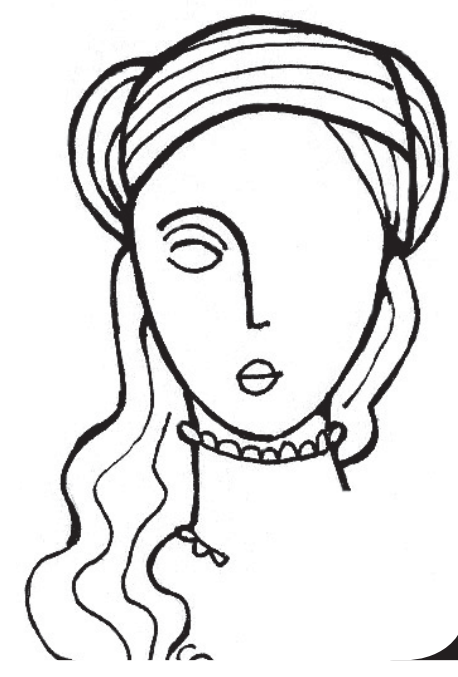

\title{
Machado de Assis en la búsqueda de la sonata de lo absoluto
}

\section{Patricia Vilcapuma Vinces}

Si Machado de Assis existió, Brasil es posible

Nelida Piñón

1 n su estudio sobre la desterritorialización de la producción literaria latinoamericana (entre otros temas como la evolución de los estudios de literatura y la re-visión del sujeto latinoamericano desde el centro), Nara Araújo sostiene con mucho acierto que los autores periféricos han desestabilizado al canon con sus «historias [sic] ex-céntricas colocando sus geografías literarias en nuevos mapas literarios» (cf. Araújo 2004: 24, el énfasis es nuestro). Curioso juego de palabras de esta proposición que trae al tema la excentricidad, una de las características más observadas en los autores modernos, y, así vista, un punto de coincidencia entre los periféricos y el Centro. Finalmente, es también muy cierto que el adentro «está constituido por el afuera» (Derrida apúd Araújo 2004: 22). Estas discusiones, que han dado importantísimos resultados y visiones, han revisitado y repasado anteriores proyectos de geografías literarias cuyo mayor propósito era la constitución de una identidad que asiente una «originalidad» con la cual legitimarlas. Negar la tradición, como se ha comprobado ya en algunos bosquejos de mapas nacionalistas, fue un intento descabellado, más aún tratándose de naciones con un pasado signado por la invasiones españolas, en el caso de Perú, o portuguesas en el caso de Brasil. El progreso y cuestionamiento de estas cuestiones trajeron, además, gracias a nuevas aperturas e interés por la "periferia», el redescubrimiento de producciones fabulosas y tan exquisitas en inquietudes que sobrepasan 
a la época de su creación. Son, pues, sobrevivientes al "espíritu del tiempo», como afirmara Antonio Candido al referirse a Machado de Assis (1839-1908), el ejemplo máximo de ello; o una «especie de milagro», en palabras de Harold Bloom, que demostraría cómo «el genio literario es independiente del tiempo y del lugar» (2005: 789).

En Machado de Assis, milagro de la posibilidad, el recuperar la tradición es «problemático». Biagio D’Angelo analiza muy bien este punto en su estudio «Trópico del cuento. Machado de Assis y la tradición literaria occidental». En este señala la cualidad sui géneris de este aspecto de la narrativa del brasileño: «de una parte la tradición del pasado, excepcionalmente no nacionalista, o sea, no [sic] brasilera, con las lecturas y las glosas interpretativas de Machado [...]; de la otra, la tradición de una modernidad que Machado inaugura, sin conocerla [...]» (2004: 30). Aquí encontramos la clave de su obra: puede brasileñamente hacer posible la universalidad, la modernidad, la actualidad de su prosa gracias a la exploración de temas esenciales. Diríamos, también, que encontramos en este narrador excepcional de cuentos la «bendita manía de contar» — a la que siempre se refería García Márquez-, ese don natural de los latinoamericanos que borra las líneas de los mapas, que nos une desde siempre y que hace posible Latinoamérica.

\section{La búsqueda de la sonata de lo absoluto}

1 Uno de los temas más recurrentes de la prosa de ficción machadiana es la búsqueda de la perfección; por ello, en sus textos se percibe una especie de desencanto, una cura contra el poder de los estereotipos «hadas» del romanticismo maniqueo de la época. Se vale para este trabajo de una exploración casi obsesiva de «las infinitas posibilidades de la realidad» (D’Angelo 2004: 43) que ayudan al creador a poner en jaque aquella cotidianeidad anodina exenta de preguntas. Y sobre la base de historias simples, algunas hasta absurdas, esboza (no responde, trabajo que deja al lector provocado constantemente en la narración) estas preguntas ante la imposibilidad de entendimiento de las contradicciones de la vida. Esa insatisfacción propia del escritor «deicida» — que cree como Maria Regina, protagonista del "Trío en la menor», que «la creación era un libro fallado e incorrecto»—, todavía inconforme con este acto, que en el fondo lo deja en la más profunda soledad y en la negación de la esperanza («la esperanza aún los hizo reincidentes, mas todo muere, hasta la esperanza»), hace que ya no sea la muerte del creador que dé origen a su mundo posible, sino la del autornarrador, la creación más cercana a su imagen —irónicamente sería su propia anulación-, y en un acto más de pretensiosa desesperación, da inicio a un ciclo donde es un difuntoautor que una y otra vez es recreado por un lector. Es decir, Bras Cubas —el personaje 
quizá más celebrado de la prosa machadiana - en el fondo no acepta, contradictoriamente incluso a su pesimismo, lo que su visión machadianamente lúcida de la vida le anticipa para los tiempos de «los post y de tantas muertes (la del sujeto, la de la muerte de la muerte del sujeto, la de la novela, la del socialismo "real” y el fin de la historia)" (Araújo 2004: 29): la muerte del autor y el nacimiento del lector. Este dilema angustiante, sobre la naturaleza de la creación literaria, es parte de la discusión dentro del propio texto y eje importante de la narrativa de Machado de Assis.

Así nos encontramos, en el bosque narrativo del creador de Memorias Póstumas de Brás Cubas (2004 [1880]), con el personaje principal de «Trío en la menor» (Várias histórias, 1896). Ante su indecisión para la elegir entre dos hombres, Maria Regina es condenada, a causa de un tercero, de un caballero inexistente (mas posible en su imaginación y luego también en la prosa de Calvino en la que El caballero inexistente [1959] desaparece a causa de la frustración de alcanzar la perfección en la unión amorosa con Priscilla), que reúne las cualidades más «perfectas» de las dos opciones que se le presentan, a «oscilar por toda la eternidad entre dos astros incompletos, al son de esta vieja sonata de lo absoluto: la, la, la...». La doble lectura de Maria Regina, que por momentos se entrecruzan, la condena a deshacer este ideal o mejor dicho la lleva a mantener a ese espectro, que bien podría haber sido el autor de su nueva vida, su complemento, si este ideal de perfección humana hubiera existido. Esta situación que se le presenta, donde puede tener solamente lo uno sin lo otro, no le permite realizarse como individuo; no le permite, pues, alcanzar la totalidad de su existencia. Ella, desde un inicio, ha sido despojada de la capacidad de decisión, de la posibilidad de alcanzar su ideal de absoluto.

2. La música es otro de los elementos usados por Machado de Assis y, sin duda, el más valioso al momento de plantear dilemas como el de "Trío en la menor». ${ }^{1}$ Planteado como una sonata, el cuento está impregnado de referencias musicales y, es precisamente, oyendo una sonata que Maria Regina puede liberarse de sus dos opciones y hacer uso de su libertad creadora para concebir "una criatura perfecta y única», unión de la belleza juvenil de Maciel y la profundidad espiritual del maduro Miranda. La música, siendo la más libre de todas las artes, ayuda a elevar su alma "por encima de sí misma" porque "todo lo que pertenece al espíritu es superior a lo que existe en estado natural» (Hegel apúd Estrada Herrero1988: 613).

\footnotetext{
1 Ya en otros cuentos, como «Un hombre célebre» (Várias histórias), se identifica una correspondencia entre el tiempo de su narrativa y el tiempo musical. Véase para profundizar sobre este tema el estudio Sem Receita: Ensaios e Cançôes de José Miguel Wisnik (2004), y el artículo "Ritmos do popular no erudito: política e música em Machado de Assis», de Idelber Avelar (disponible en <www.idelberavelar.com/abralic/txt_19. pdf>. Consulta hecha en 16/08/2007).
} 
Machado estructura el cuento en forma de sonata cuyo título inmediatamente refiere al trío formado por los personajes Maciel, Maria Regina y Miranda. "Adagio Cantabile», corresponde al primer «movimiento». En este se expone, pausadamente, la situación de los dos pretendientes en el alma curiosa de perfección de Maria Regina. En "Allegro ma non troppo" (alegre 'mas no mucho'), el desarrollo de la narrativa depende ahora de las técnicas del destino: la abuela y la joven son testigos de un acto heroico protagonizado por Maciel. Por un momento, la muchacha cree descubrir en este "destello" de perfección un motivo para acabar con la indecisión. Pero pronto se dará cuenta de que el encanto se acaba y en "Allegro appassionato», Miranda, el otro pretendiente, «ingenioso y fino y hasta profundo», ayudará a hacer más complicada la situación. Ambos sabían que eran rivales, mas no contaban con que ella, observando las carencias de los dos, «completó uno por el otro» y que «la música [la sonata] iba ayudando a la ficción».

Machado de Assis recurre a Shakespeare y a su Sueño de una noche de verano para «salvar» a Maria Regina: ella se ha convertido en Titania, reina de las hadas, que bajo los efectos de un encanto, en su sueño solamente ve formas bellas - y a su criatura perfecta«sin advertir que la cabeza era de asno».

En «Minuetto», la parte final, la muchacha concluye tras su indecisión, que provocó que los pretendientes terminaran por aborrecerla, y sus ansias «del astro perfecto», que la creación es imperfecta. Así, sumida en su sueño termina atrapada en él, condenada — y sin entender- a "oscilar por toda la eternidad entre dos astros incompletos».

3. Con esta memoria póstuma del espíritu inquieto de Machado de Assis esperamos contribuir o quizá aproximarnos a su sonata de lo absoluto, producto de una singular insatisfacción. Su genialidad, creemos, es la mejor respuesta a esta búsqueda de la absoluto; pasarán «diez, veinte, treinta días» — como el tiempo de Maria Regina en el cuento—, quizá años, siglos, y quien lea nuevamente su magnífica prosa o quien ya "conozca la técnica del destino», como enfatiza el narrador de "Trío en la menor», conocerá de inmediato que él, a pesar de sus dilemas y contradicciones, actitud muy humana por cierto, representa al ser humano que aun con una genialidad creadora reconoce y necesita algo más que sobrepasa su propia humanidad. Reconocer esto ya es un gran paso para que Maria Regina pueda abrazar la realidad toda y no sufra la autocondena de su soledad. 


\section{BIBLIOGRAFÍA}

Araújo, Nara

2004 «Desterritorialización, posdisciplinariedad y posliteratura». En Bittencourt, Gilda Neves; Léa dos S. Masina y Rita T. Schmidt (org.as). Geografias literárias e culturais: espaços/temporalidades. Porto Alegre: UFRGS, 2004, pp. 19-34.

Avelar, Idelber

2006 «Ritmos do popular no erudito: política e música em Machado de Assis». En O biscoito fino e a massa. <www.idelberavelar.com/abralic/txt_19.pdf>. Consulta hecha en 16/08/2007.

BLoom, Harold

2005 Genios. Un mosaico de cien mentes creativas y ejemplares. Bogotá: Norma.

D’Angelo, Biagio

2004 «Trópico del cuento. Machado de Assis y la tradición literaria occidental». En Saraiva, Juracy Assman y Biagio D’Angelo (orgs.). Papeles sueltos. Antología de cuentos de J. M. Machado de Assis. Lima: Fondo Editorial UCSS, pp. 29-48.

Estrada Herrero, David

1988 Estética. Barcelona: Herder.

MaCHAdo DE Assis, Joaquim Maria

2004 [1880] Memórias póstumas de Bras Cubas. Bogotá: Norma. 


\section{Thrío en la menor}

\section{ADAGIO CANTABILE}

Maria Regina acompañó a la abuela hasta el cuarto, se despidió y se fue al suyo. La mucama que la servía, a pesar de la familiaridad que existía entre ellas, no pudo arrancarle una palabra, y salió, media hora después, diciendo que Nhanhã estaba muy seria. Luego que quedó sola, Maria Regina se sentó al pie de la cama, con las piernas extendidas, los pies cruzados, pensando.

La verdad pide que diga que esta moza pensaba amorosamente en dos hombres al mismo tiempo, uno de veintisiete años, Maciel; otro de cincuenta, Miranda. Convengo que es abominable, pero no puedo alterar el aspecto de las cosas, no puedo negar que si los dos hombres están enamorados de ella, ella no lo está menos de ambos. Una exquisita, en suma; o, para hablar como las amigas de colegio, una insensata. Nadie le niega corazón excelente y espíritu limpio; pero la imaginación es que es el mal, una imaginación adusta y ambiciosa, insaciable principalmente, adversa a la realidad, sobreponiendo a las cosas de la vida otras de sí misma; de ahí curiosidades irremediables.

La visita de los dos hombres (que la enamoraban de a poco) duró cerca de una hora. Maria Regina conversó alegremente con ellos, y tocó en el piano una pieza clásica, una sonata que hizo a la abuela dormitar un poco. Finalmente, discutieron de música. Miranda dice cosas pertinentes acerca de la música moderna y antigua; la abuela tenía una predilección por Bellini y su Norma, y habló de las tocadas de su tiempo, agradables, saudosas y principalmente claras. La nieta coincidía con las opiniones de Miranda; Maciel concordó cortésmente con todos.

Al pie de la cama, Maria Regina reconstruía ahora todo eso, la visita, la conversación, la música, el debate, los modos de ser de uno y de otro, las palabras de Miranda y los bellos ojos de Maciel. Eran las once de la noche, la única luz del cuarto era la lamparita, todo convidaba al sueño y al devaneo. Maria Regina, a fuerza de recomponer la noche, vio allí dos hombres al pie de ella, los oyó, y conversó con ellos durante una porción de minutos, treinta o cuarenta, al son de la misma sonata tocada por ella: la, la, la...

\footnotetext{
Traducción del portugués de Patricia B. Vilcapuma Vinces.
} 


\section{ALLEGRO MA NON TROPPO}

Al día siguiente, la abuela y la nieta fueron a visitar a una amiga en Tijuca. Al regreso, el carruaje derribó a un niño que atravesaba la calle, corriendo. Una persona que vio esto, se arrojó a los caballos y, poniendo en peligro su propia vida, consiguió detenerlos y salvar al pequeño, que apenas quedó herido y desmayado. Gente, tumulto, la madre del muchachito acudió en lágrimas. Maria Regina descendió del carro y acompañó al herido hasta la casa de la madre, que era allí cerca.

Quien conoce la técnica del destino adivina luego que la persona que salvó al pequeño fue uno de los dos hombres de la otra noche; fue Maciel. Hechos los primeros auxilios, Maciel acompañó a la moza hasta el carruaje y aceptó el lugar que la abuela le ofreció hasta la ciudad. Estaban en Engenho Velho. En el carruaje es que Maria Regina vio que el joven traía la mano ensangrentada. La abuela preguntaba a menudo si el pequeño estaba muy mal, si sobreviviría; Maciel le dijo que las heridas eran leves. Después contó el accidente: estaba parado, en la calzada, esperando que pasase un tílburi, cuando vio al pequeño atravesar la calle por delante de los caballos; compredió el peligro, y trató de evitarlo, o disminuirlo.

- Pero está herido, dice la vieja.

- Cosa de nada.

—Está, está, insistió la moza; puede curarse también.

-No es nada, insistió él; fue un arañón, limpio esto con un pañuelo.

No tuvo tiempo de sacar el pañuelo; Maria Regina le ofreció el suyo. Maciel, conmovido, se lo puso sobre la herida, pero dudó en mancharlo. Úsalo, Úsalo, le decía ella; y viéndolo avergonzado, lo sacó y enjuagó, ella misma, la sangre de la mano.

La mano era bonita, tan bonita como el dueño; pero parece que él estaba menos preocupado por la herida de la mano que por lo arrugado de sus puños. Conversando, miraba para estos disimuladamente y los escondía. Maria Regina no veía nada, lo veía a él, le veía principalmente la acción que acababa de realizar, y que le ponía una aureola. Comprendió que la naturaleza generosa saltaba por encima de los hábitos pausados y elegantes del mozo, para arrancar a la muerte un niño que él ni conocía. Hablaron del asunto hasta la puerta de la casa de ellas; Maciel rechazó, agradeciendo, el carruaje que ellas le ofrecían, y se despidió hasta la noche.

— ¡Hasta la noche!, repitió Maria Regina. 
Lo esperó ansiosa. Él llegó, cerca de las ocho de la noche, trayendo una cinta negra enrollada en la mano, y ofreció disculpas por venir así; pero le dijeron que era bueno poner alguna cosa y obedeció.

—iPero está mejor!

—Estoy bien, no fue nada.

—Venga, venga, le dijo la abuela, desde el otro lado de la sala. Siéntese aquí junto a mí: el señor es un héroe.

Maciel oía sonriendo. Había pasado ya el ímpetu generoso, comenzaba a recibir los dividendos del sacrifício. El mayor de ellos era la admiración de Maria Regina, tan ingenua y tan grande, que olvidaba a la abuela y la sala. Maciel se sentó al lado de la vieja. Maria Regina enfrente de ambos. Mientras la abuela, restablecida del susto, contaba las conmociones que padeciera, al principio sin saber de nada, después imaginando que el niño había muerto, los dos miraban uno para el otro, discretamente, y al final ya sin pensarlo. Maria Regina preguntaba a sí misma dónde hallaría mejor novio. La abuela, que no era miope, encontró la contemplación excesiva, y habló de otra cosa; pidió a Maciel algunas noticias de sociedad.

\section{ALLEGRO APPASSIONATO}

Maciel era hombre, como él mismo decía en francés, très répandu; sacó de la faltriquera una porción de novedades menudas e interesantes. La mayor de todas fue la de estar deshecho el compromiso matrimonial de cierta viuda.

— ¡No me diga eso!, exclamó la abuela. ¿Y ella?

-Parece que fue ella misma que lo deshizo: lo cierto es que estuve anteayer en el baile, danzó y conversó muy animada. ¡Oh! más allá de la noticia, lo que causó más impresión en mí fue el collar que ella llevaba, magnífico...

- ¿Con una cruz de brillantes?, preguntó la vieja. Lo conozco; es muy bonito.

-No, no es ese.

Maciel conocía el de la cruz, que ella llevara a la casa de un Mascarenhas; no era ese. Este otro todavía hace pocos días estaba en la tienda del Resende, una cosa linda. Y describiéndolo todo, número, disposición y corte de las piedras, concluyó diciendo que fue la joya de la noche.

—Para tanto lujo era mejor casarse, apreció maliciosamente la abuela. 
-Concuerdo que la fortuna de ella no da para eso. ¡Ahora, espere! Voy mañana, al Resende, por curiosidad, para saber el precio por el que lo vendió. No fue barato, no podía ser barato. -Pero ¿por qué es que se deshizo el compromiso?

-No pude saber; pero tengo que cenar el sábado con Venancinho Corrêa, y él me cuenta todo. ¿Sabe que aún es pariente de ella? Buen joven; está completamente peleado con el barón...

La abuela no sabía de la pelea; Maciel se la contó de principio a fin, con todas sus causas y agravantes. La gota que derramó el vaso fue un comentario que se hizo en la mesa de juego una alusión al defecto de Venancinho, que era zurdo. Le contaron esto, y él rompió enteramente sus relaciones con el barón. Lo bonito es que los compañeros del barón se acusaron unos a los otros de haber sido los que contaron las palabras de este. Maciel declaró que era regla suya no repetir lo que oía en la mesa de juego, porque es lugar en que hay cierta franqueza.

Después hizo una estadística de la calle del Oidor, en la víspera, entre una y cuatro horas de la tarde. Conocía los nombres de las haciendas y todos los colores modernos. Citó las principales toilettes del día. La primera fue la de Mme. Pluma Maia, bahiana distinta, très pschutt. La segunda fue la de Mlle. Pedrosa, hija de un magistrado de São Paulo, adorable. Y apuntó tres más, comparó después a las cinco, dedució y concluyó. Algunas veces se olvidaba y hablaba francés; puede que no fuese olvido, sino a propósito; conocía bien el idioma, se expresaba con facilidad y alguna vez había dicho este axioma etnológico: que hay parisienses en todas partes. En el camino, explicó un problema de cartas.

—La señora tiene cinco trunfos de as de espadas y manilla, tiene rey y dama de copas...

Maria Regina iba pasando de la admiración al hastío; agarrábase aquí y allí, contemplaba la figura moza de Maciel, recordaba la bella acción de aquel día, pero ni eso; el hastío no tardaba en absorverla. No había remedio. Entonces recurrió a una singular idea. Trató de combinar a los dos hombres, el presente con el ausente, mirando para uno, y escuchando al otro de memoria; recurso violento y doloroso, pero tan eficaz, que ella pudo contemplar por algún tiempo una criatura perfecta y única.

De repente, apareció el otro, el propio Miranda. Los dos hombres se saludaron fríamente; Maciel se demoró aún unos diez minutos y salió.

Miranda se quedó. Era alto y seco, fisonomía dura y helada. Tenía el rostro cansado, los cincuenta años confesábanse tales, en los cabellos grisáceos, en las arrugas y en la piel. Solo los ojos contenían alguna cosa menos envejecida. Eran pequeños, y escondíanse por debajo de sus vastas cejas; pero allá, al fondo, cuando no estaban pensativos, centellaban de juventud. La abuela le preguntó, luego que Maciel salió, si ya tenía noticia del accidente 
de Engenho Velho, y lo contó con exageramientos, pero el otro oía todo sin admiración ni envidia.

- ¿No lo encuentra sublime?, preguntó ella, al terminar.

—Creo que él salvó tal vez la vida a un desalmado que algún día, sin conocerlo, puede meterle un cuchillo en la barriga.

— ¡Oh!, protestó la abuela.

-O también conociéndolo, corrigió él.

- No sea malo, intervino Maria Regina; el señor era también capaz de hacer lo mismo, si allí estuviese.

Miranda sonrío de un modo sarcástico. La risa le acentuó la dureza de su fisonomía. Egoísta y malo, este Miranda primaba por un lado único: espiritualmente, era completo. Maria Regina hallaba en él el traductor maravilloso y fiel de una porción de ideas que luchaban dentro de ella, vagamente, sin forma o expresión. Era ingenioso y fino y hasta profundo, todo sin pedanterías, y sin meterse por terrenos cerrados, antes casi siempre en la planicie de las conversaciones ordinarias; tan cierto es que las cosas valen por las ideas que nos sugieren. Tenían ambos los mismos gustos artísticos; Miranda estudió derecho para obedecer al padre; su vocación era la música.

La abuela, previendo la sonata, preparó el alma para algunos ratos de sueño. Además, no podía admitir tal hombre en el corazón; lo encontraba aburrido y antipático. Se calló al poco de algunos minutos. La sonata vino, en medio de una conversación que Maria Regina encontró deliciosa, y no vino sino porque él le pidió que tocase; él quedaría encantado de oírla.

-Abuela, dice ella, ahora hay que tener paciencia...

Miranda se aproximó al piano. Cerca de las arandelas, la cabeza de él mostraba toda la fatiga de los años, al paso que la expresión de la fisonomía era mucho más de piedra e hiel. Maria Regina notó la graduación, y tocaba sin mirar para él; difícil cosa, porque, si él hablaba, las palabras le entraban tanto por el alma, que la moza insensiblemente levantaba los ojos, y daba luego con un viejo ruin. Entonces es que se acordaba de Maciel, de sus años en flor, de la fisionomía franca, tierna y buena, y finalmente de la acción de aquel día. Comparación tan cruel para Miranda, como fuera para Maciel el cotejo de sus espíritus. Y la moza recurrió a la misma idea. Completó uno por el otro; escuchaba a este con el pensamiento en aquel; y la música iba ayudando a la ficción, indecisa al principio, pero luego viva y acabada. Así Titania, oyendo enamorada el cántico del tejedor, le admiraba las bellas formas, sin advertir que la cabeza era de asno. 


\section{MINUETTO}

Diez, veinte, treinta días pasaron después de aquella noche, y aún más veinte, y después más treinta. No hay cronología cierta; mejor es quedar en el olvido. La situación era la misma. Era la misma insuficiencia individual de los dos hombres, y el mismo complemento ideal por parte de ella; de ahí un tercer hombre, que ella no conocía.

Maciel y Miranda desconfiaban uno del otro, se detestaban más y más, y padecían mucho, Miranda, principalmente, que era pasión de última hora. Al final acabaron aborreciendo a la joven. Esta los vio ir poco a poco. La esperanza aún los hizo reincidentes, mas todo muere, hasta la esperanza, y ellos saldrán para nunca más. Las noches fueron pasando, pasando... Maria Regina comprendió que estaba acabado.

La noche en que se persuadió bien de esto fue una de las más bellas de aquel año, clara, fresca, luminosa. No había luna; pero nuestra amiga aborrecía a la luna — no se sabe bien por qué-, o porque brilla de préstamo, o porque toda la gente la admira, y puede ser que por ambas razones. Era una de sus exquisitices. Ahora otra.

Había leído en la mañana, en una noticia de periódico, que hay estrellas dobles, que nos parecen un solo astro. En vez de ir a dormir, se apoyó en la ventana del cuarto mirando para el cielo, a ver si descubría alguna de ellas; inútil esfuerzo. No descubriéndola en el cielo, la buscó en sí misma, cerró los ojos para imaginar el fenómeno; astronomía fácil y barata, pero no sin riesgo. Lo peor que ella tiene es poner a los astros al alcance de la mano; de modo que, si la persona abre los ojos y ellos continúan fulgurando allá en la cima, grande es el desconsuelo y cierta la blasfemia. Fue lo que sucedió aquí. Maria Regina vio dentro de sí la estrella doble y única. Separadas, valían bastante; juntas, daban un astro espléndido. Y ella quería el astro espléndido. Cuando abrió los ojos y vio que el firmamento quedaba tan alto, concluyó que la creación era un libro fallado e incorrecto, y se desesperó.

En el muro de la chacra vio entonces una cosa parecida a dos ojos de gato. $\mathrm{Al}$ principio tuvo miedo, pero advirtió luego que no era más que la reproducción externa de los dos astros que ella viera en sí misma y que habían quedado impresos en la retina. La retina de esta moza hacía reflejar acá afuera todas sus imaginaciones. Refrescándose al viento se recogió, cerró la ventana y se metió en la cama.

No durmió de inmediato, por causa de dos rodelas de ópalo que estaban incrustadas en la pared; percibiendo que era aún una ilusión, cerró los ojos y durmió. Soñó que moría, que el alma de ella, elevada a los aires, volaba en la dirección de una bella estrella doble. El astro se desdobló, y ella voló para una de las dos porciones; no encontró allí la sensación primitiva y se despeñó para otra; igual resultado, igual regreso, y empezó a andar de una 
para otra de las dos estrellas separadas. Entonces una voz surgió del abismo, con palabras que ella no entendió.

—Es tu pena, alma curiosa de perfección; tu pena es oscilar por toda la eternidad entre dos astros incompletos, al son de esta vieja sonata de lo absoluto: la, la, la... 